Supplement of The Cryosphere, 11, 2305-2327, 2017

https://doi.org/10.5194/tc-11-2305-2017-supplement

(C) Author(s) 2017. This work is distributed under

the Creative Commons Attribution 3.0 License.

(c) (1)

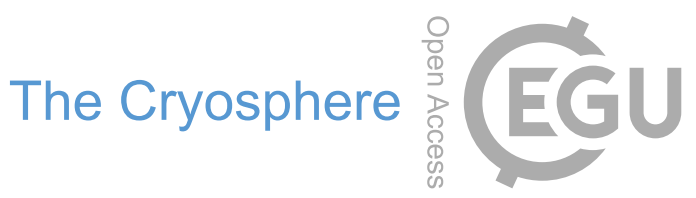

Supplement of

\title{
Discovery and characterization of submarine groundwater discharge in the Siberian Arctic seas: a case study in the Buor-Khaya Gulf, Laptev Sea
}

\author{
Alexander N. Charkin et al. \\ Correspondence to: Alexander N. Charkin (charkin@poi.dvo.ru)
}

The copyright of individual parts of the supplement might differ from the CC BY 3.0 License. 


\section{Supplement Table S1}

Resistivity in the bottom sediments in the wider Lena Delta area.

\begin{tabular}{|c|c|c|c|c|}
\hline TEM stations & Latitude ${ }^{\circ} \mathbf{N}$ & Longitude ${ }^{\circ} \mathbf{E}$ & Thickness (m) & Resistivity ( $\Omega$ m) \\
\hline \multirow[t]{5}{*}{1} & \multirow[t]{5}{*}{7140.807} & \multirow{5}{*}{12946.942} & 2(Ice) & 200 \\
\hline & & & 6,5 & 0,67 \\
\hline & & & 35,8 & 2 \\
\hline & & & $>570$ & 71 \\
\hline & & & - & 2 \\
\hline \multirow[t]{5}{*}{2} & \multirow[t]{5}{*}{7148.000} & \multirow[t]{5}{*}{1301.0002} & 2(Ice) & 200 \\
\hline & & & 5,76 & 1,1 \\
\hline & & & 52,5 & 8,33 \\
\hline & & & 110 & 3,4 \\
\hline & & & - & $>350$ \\
\hline \multirow[t]{5}{*}{3} & \multirow[t]{5}{*}{7147.584} & \multirow[t]{5}{*}{1303.260} & 2 (Ice) & 200 \\
\hline & & & 11,6 & 0,95 \\
\hline & & & 46,4 & 1,97 \\
\hline & & & 727 & 80 \\
\hline & & & - & 4 \\
\hline \multirow[t]{5}{*}{4} & \multirow[t]{5}{*}{7140.5474} & \multirow[t]{5}{*}{1307.8775} & 2 (Ice) & 200 \\
\hline & & & 9,55 & 1 \\
\hline & & & 19 & 1,7 \\
\hline & & & 805 & 45 \\
\hline & & & - & 2 \\
\hline
\end{tabular}

